\title{
Effects of Reclaimed Water on the Characteristics of Dimethyl Phthalate Adsorption on Sediments
}

\author{
Zigong Ning ${ }^{1,2}$, Pengxiang $\mathrm{Li}^{2}$, Shuang Zhou ${ }^{3}$, Yunkai $\mathrm{Li}^{1{ }^{1,}}$, Munehide Ishiguro ${ }^{4}$, Wei \\ Zhao $^{1}$, Meie Wang ${ }^{5}$
}

\begin{abstract}
Adsorptions of Dimethyl Phthalate (DMP) on three sediments in both reclaimed and ultrapure water were studied using the batch technique and the effects of reclaimed water on it were clarified. The data were interpreted by using Freundlich and Dubinin-Radushkviech models. The values of 1 / $\mathrm{n}$ were among 0.207 to 0.766 , showing the presence of multiple adsorption sites on sediments. Compared with the ultrapure water as the background solution, the adsorption capacities of sediments for DMP were reduced in case of reclaimed water due to the competition of substances in reclaimed water. The mean adsorption energy, E, is smaller in the reclaimed water than that in ultrapure water. Water Environ. Res., 89, 274 (2017).
\end{abstract}

KEYWORDS: DMP, sediment, reclaimed water, adsorption. doi:10.2175/106143017X14839994522425

\section{Introduction}

Dimethyl phthalate (DMP) is widely used as a plasticizer to improve the flexibility and durability of polyvinyl chloride (PVC)-based plastics (Osman et al., 2013). The DMP is not chemically bound to the PVC polymer. Therefore, DMP is easily released into the environment (Staples et al., 1997). DMP has been detected in the natural water and soil (Gledhill et al., 1980). $0.36 \mu \mathrm{g} / \mathrm{L}$ of DMP was detected in the underground water near

${ }^{1}$ College of Water Resources and Civil Engineering, China Agricultural University, Beijing 100083, P.R.China.

${ }^{2}$ Graduate School of Agriculture, Hokkaido University, Kita 9 Nishi 9, Sapporo 060-0809, Japan.

${ }^{3}$ Faculty of Engineering, Hokkaido University, Sapporo, Japan.

${ }^{4}$ Research Faculty of Agriculture, Hokkaido University, Sapporo, Japan.

${ }^{5}$ State Key Laboratory of Urban and Regional Ecology, Research Centre for Eco-Environmental Sciences, Chinese Academy of Sciences, Beijing 100085, P.R.China.

"College of Water Resources and Civil Engineering, China Agricultural University, Beijing 100083, P.R.China; email: yunkai@, cau.edu. the Homestead Wastewater Treatment Plant in Florida (Foster et al., 2012). Because DMP causes the functional disturbances of nervous system of animals, it is ecologically toxic and a hazardous material (Douglas et al., 1986).

Adsorption is the main method responsible for extracting the toxic compounds from the water phase, which strongly influences the fate, behavior, bioavailability and the transport of toxic compounds in the environment. Besides, water solubility also is a determining factor controlling the environmental distribution and behaviors of DMP (Abdel daiem et al., 2012; Staples et al., 1997). Many previous works have reported about sorption behaviors of DMP on soils (Yang et al., 2013; Li et al., 2010), sediments (Gao et al., 2011; Xia et al., 2012), beads (Osman et al., 2012; Chen et al., 2007), polymer resins (Zhang et al., 2007) and carbon nanotubes (Den et al., 2006) by applying the Langmuir, Freundlich, and Dubinin-Radushkevich adsorption equations. The reclaimed water has been regarded as one of the water resources to solve water shortage problem and recover water ecosystems in big cities all over the world, such as Santee Project in Sycamore Valley (California Santee Town, United States), Nobidome River in Tokyo (Japan), Olympic Lake (Chaoyang District, Beijing), Lianshi Lake (LSL) and Xiaoyue Lake (XYL) in Yongding River (Mentougou District, Beijing) and so on. The reclaimed water is an extremely complicated multi-material coexisting system, which contains various inorganic and organic substances and microorganisms ( $\mathrm{Li}, 2012$ ). The reclaimed water is supposed to strongly influence the fates of DMP in the water ecosystem. However, the research of DMP adsorption influenced by the reclaimed water is rare.

The DMP adsorbed on sediments was studied by the batch method. The effects of reclaimed water on adsorption characteristics of DMP on sediments were analyzed. The aim of the present study is to elucidate the adsorption phenomena of DMP on sediments of urban lakes especially under the influence of reclaimed water-a multi-material coexisting system. 
Table 1-The basic physicochemical properties and particle composition of sediments.

\begin{tabular}{|c|c|c|c|c|c|c|}
\hline \multirow[b]{2}{*}{ Sediments } & \multirow[b]{2}{*}{$\begin{array}{c}\text { Organic } \\
\text { matter (g/kg) }\end{array}$} & \multirow[b]{2}{*}{$\begin{array}{c}\text { CEC } \\
\text { (mmoL/kg) }\end{array}$} & \multirow[b]{2}{*}{ pH } & \multicolumn{3}{|c|}{ Particle percentage (\%) } \\
\hline & & & & $\begin{array}{l}\text { Sand } \\
1.0-0.05\end{array}$ & $\begin{array}{c}\text { Silt } \\
0.05-0.002\end{array}$ & $\begin{array}{c}\text { Clay } \\
<0.002 \mathrm{~mm}\end{array}$ \\
\hline LSL & 83.4 & 174 & 7.68 & 38 & 56 & 6 \\
\hline $\mathrm{DXL}$ & 10.4 & 207 & 8.18 & 22 & 46 & 32 \\
\hline $\mathrm{XYL}$ & 67.7 & 10.7 & 7.8 & 64.4 & 30.6 & 5 \\
\hline
\end{tabular}

Note: Organic matter: Soil-Determination of Organic Carbon-Potassium Dichromate Oxidation Spectrophotometric Method; pH: ISO 10390: 2005(E); CEC: Ammonium Acetate Method; Particles Diameter percentage(\%): Hydrometer Method.

\section{Materials and Methods}

Materials. Reclaimed Water. The reclaimed water used in the present study was obtained from a reclaimed water plant located in Qinghe Town, Haidian District of Beijing. The wastewaters from the around areas in Beijing, such as Zhongguancun Science Park, Qinghe River Industrial Park, Residential Quarter and so on, are collected as the wastewater sources of the sewage water plant of Qinghe, which are treated by the Anaerobic Anoxic Oxic technology $\left(\mathrm{A}^{2} / \mathrm{O}\right)$ to remove nitrogen and phosphorus. The $\mathrm{A}^{2} / \mathrm{O}$ process consists of an anaerobic tank followed by an anoxic anaerobic tank. Its effluents are regarded as the sources of reclaimed water plant of Qinghe. The membrane treatment and process of ozone are used to make the reclaimed water. The qualities of reclaimed water used in this research were as follows: the total organic carbon (TOC) (combustion oxidation non-dispersive infrared absorption method) was $6.06 \mathrm{mg} / \mathrm{L}, \mathrm{COD}_{\mathrm{Cr}}$ (Dichromate Method) 28.5 $\mathrm{mg} / \mathrm{L}$ and $\mathrm{BOD}_{5}$ (Dilution and Seeding method) $3.6 \mathrm{mg} / \mathrm{L}$.

Sediments. The sediments were selected from top fresh sediments $(0-10 \mathrm{~cm})$ of Lianshi Lake (LSL), Xiaoyue Lake (XYL), and Daoxiang Lake (DXL) in Beijing city in September in 2011. LSL and XYL are located in Mentougou District of Beijing. The reclaimed water from the plant of Qinghe is directly discharged into LSL and XYL. DXL is located in Haidian District of Beijing. The sediment samples were air-dried in a laboratory. The sundries (such as stones and roots) were removed. The dry samples were ground and passed through a 1 $\mathrm{mm}$ screen. The basic physicochemical properties and particle composition of the sediments are shown in Table 1 . The content of organic matter in sediments were measured according to SoilDetermination of Organic Carbon-Potassium Dichromate Oxidation Spectrophotometric Method. The Ammonium Acetate Method was applied to measure the cation exchange capacity of sediments. The distribution of particles diameter was measured according to the method of Hydrometer. According to soil texture triangle of the USDA classification system, the sediments from LSL, DXL and XYL were the silty clay, silty clay loam and sandy loam, respectively.

Chemical Agent. The Dimethyl Phthalate is 99\% analytical grade (bought from Dr. Hielscher Company, Germany). Acetone, hexane, methylene chloride, and methanol are chromatographic pure. $\mathrm{CaCl}_{2}$ and other chemical reagents are analytical pure. The ultrapure water was obtained by Mili-Q ultrapure water instrument.
Adsorption Experiment. The experiments of DMP adsorption on the sediments were conducted by the batch method. The procedures of the experiment were as follows:

Adsorption Experiments. The sediments of $2 \mathrm{~g}$ were placed into the $50 \mathrm{~mL}$ centrifuge tube. Twenty $\mathrm{mL}$ solutions at 5, 10, 20, 50, 100 or $200 \mathrm{mg} / \mathrm{L}$ DMP (These concentrations were selected according to the result of pre-experiments, which were not shown in this text) with $1.1 \mathrm{~g} / \mathrm{L} \mathrm{CaCl}_{2}$ (increasing the solubility of DMP) in the ultrapure water were added into the tube. They were shaken for 6 hours at $25 \pm 2{ }^{\circ} \mathrm{C}$. The suspensions were centrifuged for $10 \mathrm{~min}$ at $4000 \mathrm{r} / \mathrm{min}$. The DMP concentrations in the supernatant solutions were detected by a HPLC system (1200, Agilent, USA) with UV detection. The amount of DMP adsorbed by the sediment was calculated by subtracting the amount of DMP in equilibrium solution from the total amount of initially added DMP as the following equation:

$$
q=\frac{C_{0} V-C V}{W_{S}}
$$

where $q$ is the adsorption amount per gram of the solid phase, $C_{0}$ is the initial DMP concentration of input solution, $C$ is the final DMP concentration in the solution, $V$ is the volume of the input $=$ equilibrium solution.

Experiments on the Effects of Reclaimed Water on DMP Adsorption on Sediments. Two grams of each sediment was placed into the $50 \mathrm{ml}$ centrifuge tube. Twenty $\mathrm{ml}$ solution at different DMP concentration with $1.1 \mathrm{~g} / \mathrm{L} \mathrm{CaCl}_{2}$ was prepared using the reclaimed water. It was added into the centrifuge tube. The tube was shaken for 24 hours at $25 \pm 2{ }^{\circ} \mathrm{C}$. The suspension was centrifuged and the DMP concentration in the supernatant was measured by a HPLC system (1200, Agilent, USA) with UV detection. The amount of DMP adsorbed by the sediments was calculated by subtracting the amount of DMP in equilibrium solution from the total amount of initially added DMP as described above in the equation.

Kinetics of Adsorption Experiments. A series of $2 \mathrm{~g}$ sediment samples were placed into $50 \mathrm{~mL}$ centrifuge tube, and $20 \mathrm{~mL}$ of $100 \mathrm{mg} / \mathrm{L}$ DMP solutions with $1.1 \mathrm{~g} / \mathrm{L} \mathrm{CaCl}_{2}$ in ultrapure water was added. The tubes were shaken for $0.5 \mathrm{~h}, 1.0 \mathrm{~h}, 2.0 \mathrm{~h}, 4.0 \mathrm{~h}$, $8.0 \mathrm{~h}, 12.0 \mathrm{~h}$, and $24.0 \mathrm{~h}$, respectively. The amount of DMP adsorbed by sediment was obtained as written before.

\section{Results and Discussion}

The Kinetics of DMP Adsorbed by Sediments. The effect of connect time on the DMP adsorbed on sediments is shown in 


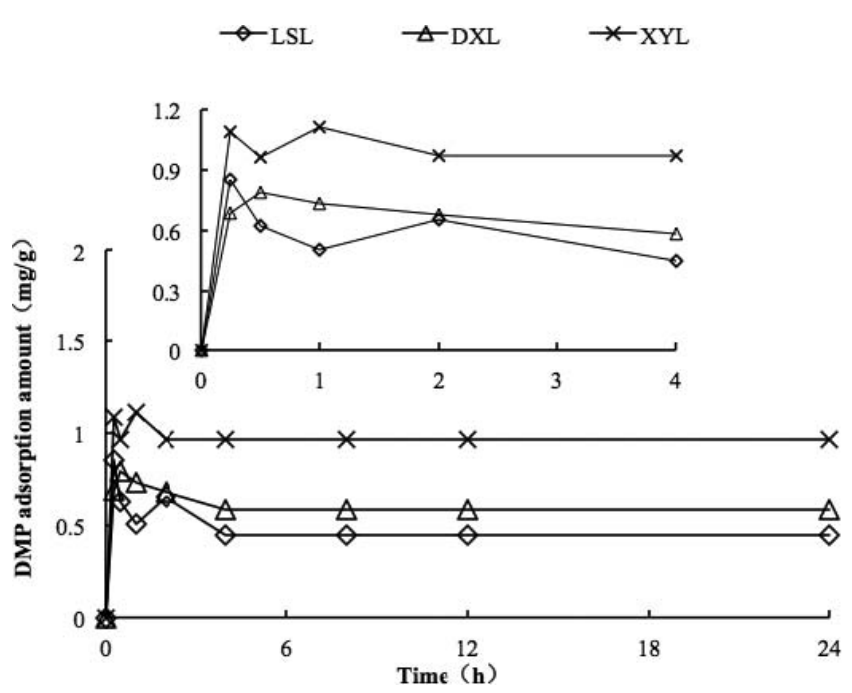

Figure 1-Kinetics of DMP adsorption on three sediments (the insert is the amplification of plots at initial time)

Figure 1. As can be seen from the Figure, the amount of DMP adsorption on three sediments increased with the contact time increasing, indicating that the rates of DMP adsorbed on sediments were rapid initially and slowed down progressively. The participation of specific functional groups and active surface site perhaps made the initial rapid DMP adsorption. After $6 \mathrm{~h}$ approximately, the rate of DMP adsorbed on sediments was almost zero, and one can find that beyond $6 \mathrm{~h}$ there was almost no further increase in the adsorption amount even though the contact time continued to $24 \mathrm{~h}$, which indicates that the equilibrium was reached within $6 \mathrm{~h}$. Therefore, the equilibrium contact time for the experiment was fixed to $6 \mathrm{~h}$.

Adsorption Isotherms of DMP on Sediments. Figure 2 shows the adsorption amount of DMP on three sediments against the equilibrium concentration. As can be seen from the Figure, the amount of DMP adsorbed on three sediments increased with the increase of its concentration in solution because the adsorption site on sediments became progressively occupied by DMP. There were almost no differences of the amount of DMP adsorbed among three sediments at low DMP concentration. However, the difference progressively increased with the increase of DMP concentration because of the difference of adsorption capacity of sediments for DMP.

Freundlich Isotherm Model. The Freundlich isotherm model is usually applied for solid surfaces, which possess multiple kinds of adsorption sites where adsorption energies are different. Theoretically, the model can be derived from the following Langmuir-Freundlich equation, which is derived analytically by integrating many local Langmuir equations for different adsorption sites (Van Riemsdijk et al., 1986).

$$
\theta=\frac{(k C)^{m}}{1+(k C)^{m}}
$$

where $\theta$ is the adsorption ratio, $C$ is the concentration and $k$ and

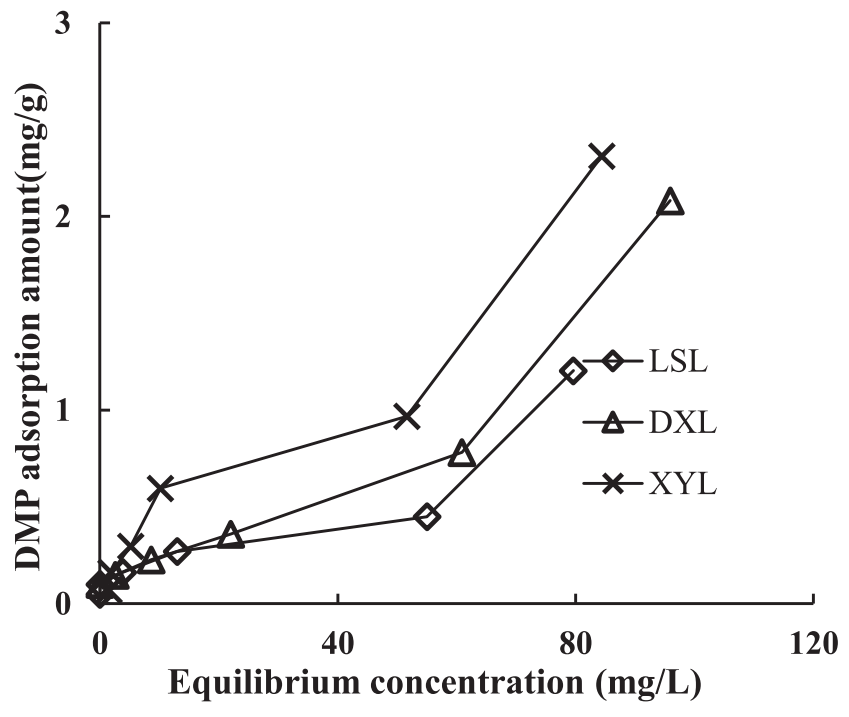

Figure 2-Adsorption isotherm of DMP on three sedimentsNote: $L S L, D X L$ and XYL represented the three sediments which from Lianshi Lake, Daoxiang Lake and Xiaoyue Lake, respectively.

$m$ are constants. When $(k C)^{m}<<1$, we obtain the Freundlich equation.

The Freundlich equation was applied to fit the isotherm of DMP adsorbed on three sediments (Freundlich et al., 1926). The linearized equation is:

$$
\log (S)=\log \left(K_{F}\right)+1 / n \log \left(C_{e}\right)
$$

where $S$ is the DMP adsorption amount per $\mathrm{g}$ of sediments, mg/ $\mathrm{g}, \mathrm{C}_{e}$ is the equilibrium solution concentration, $\mathrm{mg} / \mathrm{L}$, and $K_{F}$ and $1 / n$ are the empirical constants of the Freundlich equation. The plots of $\log (S)$ against $\log \left(C_{e}\right)$ for DMP adsorption on three sediments are shown in Figure 3a. From the slope and the intercept of the plots, one can get the values of empirical constants $1 / n$ and $K_{F}$, respectively, which are shown in Table 2.

As it can be seen from the Figure and Table, the logarithm of adsorption amount increases in proportion to the logarithm of equilibrium concentration with the high correlation coefficients $\left(r^{2}: 0.829-0.923\right)$. Meanwhile, the values of $1 / n$ for DMP adsorbed on three sediments were smaller than 1 , which showed that the process of DMP adsorbed by sediment was not a simple partition process which interacts with only one similar adsorption site, but a process of nonlinear adsorption which interacts with different multiple sites. Gao et al. (2011) reported that the DMP adsorption isotherm could adequately be fitted well to the Freundlich model $\left(R^{2}>0.981\right)$ and the DMP adsorption isotherm was nonlinear with $1 / n$ values ranging from 0.691 to 0.759 . Yang et al. (2013) reported that the values of $1 / n$ were close to 1 indicating that the partition was the main sorption mechanism for DMP adsorbed by soils. $K_{F}$ is the Freundlich sorption coefficient characterizing the sorption capacity. The different values of $K_{F}$ for different sediments are different, revealing the different sediment sorption capacity. The order of sediment sorption affinity in three sediments charac- 


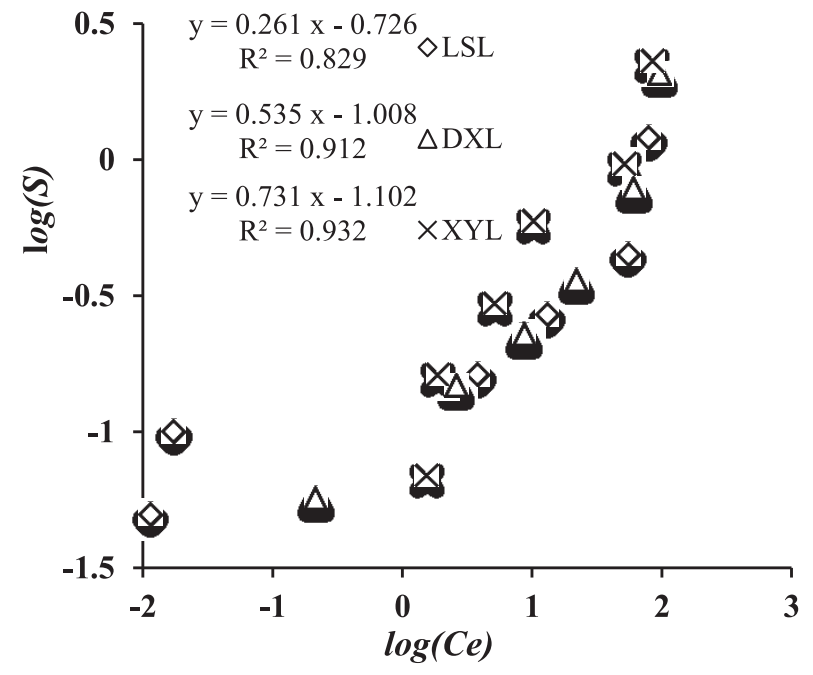

(a) Freundlich

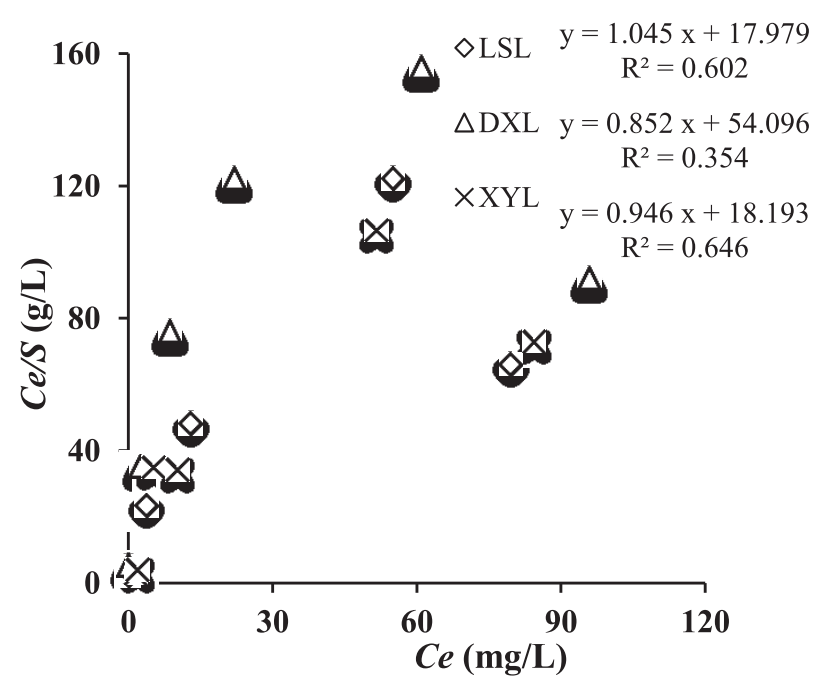

(b) Langmuir

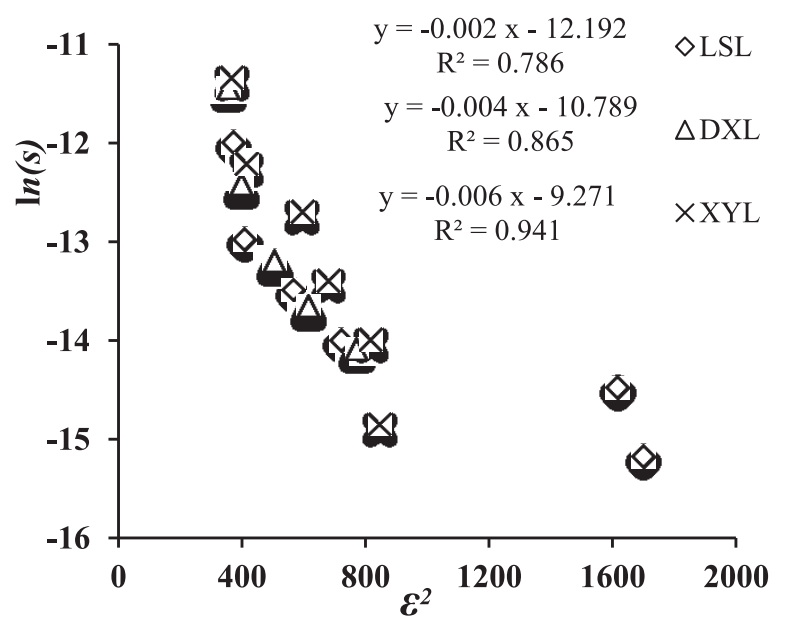

(c) Dubinin-Radushkviech terized by $K_{F}$ values are LSL $>$ DXL $>$ XYL, which is related to the type of organic matter and sediment mineral structure (Mitra et al., 1999; Yang et al., 2013). The values of $K_{F}$ were among 0.079 to 0.188 for the three sediments, and were smaller than that reported by Yang et al. (2013) and Gao et al. (2011) because of the difference of organic matter and clay contained.

Langmuir Isotherm Model. Langmuir (1918) firstly proposed the Langmuir adsorption isotherm model for the gases adsorption on solid phase, which is derived assuming a finite number of identical adsorption sites and the absence of lateral interaction between adsorbed species. Up to now, it has been widely used to describe the adsorption phenomena in solution (Gao et al., 2011; Osman et al., 2012; Khan et al., 1995). Its linearized form is as follows:

$$
C_{e} / S=1 / S_{m L} K_{L}+C_{e} / S_{m}
$$

Where $S$ is the amount of DMP adsorbed by per unit mass of sediments. $C_{e}$ is the equilibrium concentration of DMP in the equilibrium solution. $S_{m L}$ is the adsorption capacity. $K_{L}$ is the binding constant related to the free energy of adsorption $\Delta G^{0}=$ $-R T \ln \left(K_{L}\right),(R=8.3145 \mathrm{~J} /(\mathrm{mol} \cdot \mathrm{K})$ is the gas constant; $T$ is the temperature (K)) (Khan et al., 1995; El-Kamash et al., 2005). The fitted isotherm data by Langmuir model at $298 \mathrm{~K}$ was shown in Figure $3 \mathrm{~b}$, which was obtained by plotting $C_{e} / S$ against $C_{e}$.

Gao et al. (2011) successfully applied the Langmuir model to describe DMP adsorbed by sediments from the Jiamusi region of the Songhua River $\left(R^{2}=0.991\right)$. Osman et al. (2012) published the good fitting result $\left(R^{2}>0.99\right)$ of Langmuir model for DMP adsorbed by the poly macro beads, and showed that DMP adsorbed by beads was a favorable process. Den et al. (2006) researched the DMP adsorbed by carbon nanotubes, and also found that the Langmuir model could fit adsorption isotherm well $\left(R^{2}>0.98\right)$, and pointed out that Langmuir isotherm model was more suitable than Freundlich isotherm model to characterize the DMP adsorption isotherm curves. However, in the present research, the fitted results by the Langmuir model was not good for DMP adsorbed by the three sediments, while those by Freundlich model was good, which indicates that the DMP adsorption sites on sediments were highly heterogeneous.

Dubinin-Radushkviech Isotherm Model. In order to investigate the nature of the DMP sorption processes on three sediments, Dubinin-Radushkviech isotherm (Dubinin et al., 1947; Foo et al., 2010; Osman et al., 2012; Osman et al., 2013) was also verified in the linear form:

$$
\ln (S)=\ln \left(S_{m D-R}\right)-K_{D-R} \varepsilon^{2}
$$

Where $S$ is the amount of DMP adsorbed by per mass of sediments $(\mathrm{mg} / \mathrm{g}), S_{m D-R}$ is the maximum adsorption capacity $(\mathrm{mg} / \mathrm{g}), K_{D-R}$ is the Dubinin-Radushkviech isotherm constant $\left(\mathrm{mol}^{2} / \mathrm{J}^{2}\right)$, and $\varepsilon$ is the Polanyi potential $(\mathrm{J} / \mathrm{mol})$, which can be calculated as: $\varepsilon=R T \ln \left(1+1 / C_{e}\right)$ (Osman et al., 2012; Osman et

Figure 3-Freundlich, Langmuir and Dubinin-Radushkviech plot of DMP adsorption on three sediments 
Table 2-Freundlich and Dubinin-Radushkviech parameters for DMP adsorption on three sediments.

\begin{tabular}{|c|c|c|c|c|c|c|c|}
\hline \multirow[b]{2}{*}{ Sediments } & \multicolumn{3}{|c|}{ Freundlich } & \multicolumn{4}{|c|}{ Dubinin-Radushkviech } \\
\hline & $1 / n$ & $K_{F}$ & $R^{2}$ & $-K_{D-R}$ & $S_{m D-R}\left(10^{-6} \mathrm{~mol} / \mathrm{g}\right)$ & $R^{2}$ & $E(\mathrm{~kJ} / \mathrm{mol})$ \\
\hline $\begin{array}{l}\text { LSL-R } \\
\text { DXL-R }\end{array}$ & $\begin{array}{l}0.207 \\
0.213\end{array}$ & $\begin{array}{l}0.188 \\
0.098\end{array}$ & $\begin{array}{l}0.829 \\
0.912\end{array}$ & $\begin{array}{l}0.0017 \\
0.004\end{array}$ & $\begin{array}{r}5.070 \\
20.624\end{array}$ & $\begin{array}{l}0.786 \\
0.865\end{array}$ & $\begin{array}{l}17.150 \\
11.180\end{array}$ \\
\hline XYL-R & 0.688 & 0.079 & 0.932 & 0.0061 & 94.062 & 0.941 & 9.054 \\
\hline
\end{tabular}

Table 3-Freundlich and Dubinin-Radushkviech parameters for DMP adsorption on three sediments with reclaimed water.

\begin{tabular}{|c|c|c|c|c|c|c|c|}
\hline \multirow[b]{2}{*}{ Sediments } & \multicolumn{3}{|c|}{ Freundlich } & \multicolumn{4}{|c|}{ Dubinin-Radushkviech } \\
\hline & $1 / n$ & $K_{F}$ & $R^{2}$ & $-K_{D-R}$ & $S_{m D-R}\left(10^{-6} \mathrm{~mol} / \mathrm{g}\right)$ & $R^{2}$ & $E(\mathrm{~kJ} / \mathrm{mol})$ \\
\hline LSL-R & 0.342 & 0.133 & 0.870 & 0.0024 & 6.702 & 0.833 & 14.434 \\
\hline DXL-R & 0.546 & 0.072 & 0.839 & 0.0044 & 19.423 & 0.795 & 10.660 \\
\hline$X Y L-R$ & 0.766 & 0.051 & 0.954 & 0.0066 & 84.508 & 0.960 & 8.704 \\
\hline
\end{tabular}

al., 2013). Linear regression analysis was conducted using $\ln (S)$ and $\varepsilon^{2}$ and $S_{m D-R}, K_{D-R}$ and $E$ were obtained as shown in Figure $3 \mathrm{c}$ and Table 2. The mean adsorption energy $E(\mathrm{~kJ} / \mathrm{mol})$ is defined as the free energy changing when one mole of DMP is transferred to the surface of the solid from infinity in the solution. One can calculate it by equation of $E=\left(-2 K_{D-R}\right)^{-0.5}$ (Laus et al., 2010). The values of mean adsorption energy $E$ for DMP adsorbed on three sediments are larger than $8 \mathrm{~kJ} / \mathrm{mol}$ (Osman et al. 2012; Osman et al. 2013; El-Kamash et al. 2005), which indicates the chemical ion exchange. The sediment matrix containing adsorption sites with different adsorption energies (Chen et al., 2007; Gao et al., 2011) caused the difference of the mean adsorption energy $E$ of DMP adsorbed by three sediments.

Effect of Reclaimed Water on DMP Adsorbed by Sediments. The adsorption amount of DMP adsorbed by

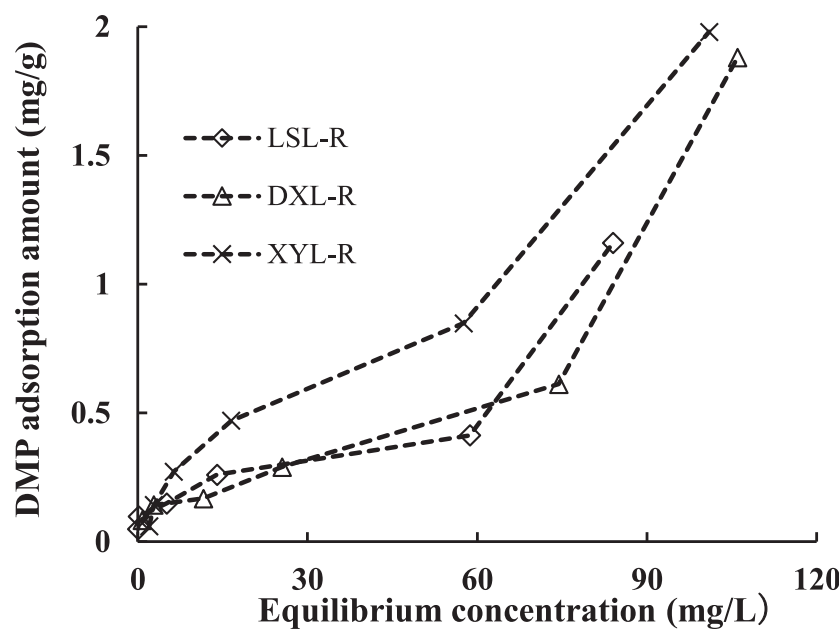

Figure 4-Adsorption isotherm of DMP on three sediments with reclaimed waterNote: $L S L, D X L$ and $X Y L$ represented the three sediments which from Lianshi Lake, Daoxiang Lake and Xiaoyue Lake, respectively. $\mathrm{R}$ represented the reclaimed water. three sediments in the reclaimed water against the equilibrium concentration $\left(C_{e}\right.$, is shown in Figure 4. One can find from the figure that the amount of DMP adsorbed by three sediments increases with the DMP concentration increasing in range of this experimental concentration ( 0 to $200 \mathrm{mg} / \mathrm{L}$ ). For the same initial DMP concentration, the adsorption amount of DMP in reclaimed water was smaller than that in the ultrapure water, because the reclaimed water was a multi-material coexisting system, containing amounts of organic matters (the concentrations of TOC, $\mathrm{COD}_{\mathrm{Cr}}$ and $\mathrm{BOD}_{5}$ were $6.06 \mathrm{mg} / \mathrm{L}, 28.5 \mathrm{mg} / \mathrm{L}$ and $3.6 \mathrm{mg} / \mathrm{L}$, respectively) and other ions (Gan et al., 2010; Hu et al., 2011), which would compete for the adsorption sites on the sediments matrix with DMP.

As it can be seen in the Figure 5, Freundlich, Langmuir and Dubinin-Radushkviech adsorption isotherm models also were applied to describe the DMP adsorbed by three sediments in reclaimed water. As it can be observed from the figure, the Langmuir model is not yet suitable for DMP adsorbed by sediments. Meanwhile, the models of Freundlich and DubininRadushkviech were applied successfully. The parameters of Freundlich and Dubinin-Radushkviech isotherm models for DMP adsorbed by three sediments are presented in Table 3.

The value of parameter $1 / \mathrm{n}$ between 0 and 1 represents the adsorption intensity and surface heterogeneity. The closer to zero the value is, the more heterogeneous the adsorption is. The value below unity implies chemical sorption process (Haghseresht et al., 1998; Foo et al., 2010). In the condition of reclaimed water, one can find that the range of value $1 / \mathrm{n}$ are between 0 and 1 , but their values are larger than that obtained in the ultrapure water. The result indicates that chemical adsorption process is still the dominant mechanism for DMP adsorbed by sediments in reclaimed water. The larger values of $1 / \mathrm{n}$ indicate the adsorption sites on sediments for DMP become less heterogeneous. The sorption sites of sediments for DMP occupied by the organic matters or ions originally remaining in reclaimed water made the values of parameters $K_{F}$ be smaller than those in ultrapure water. The DMP combining with the organic matter in 


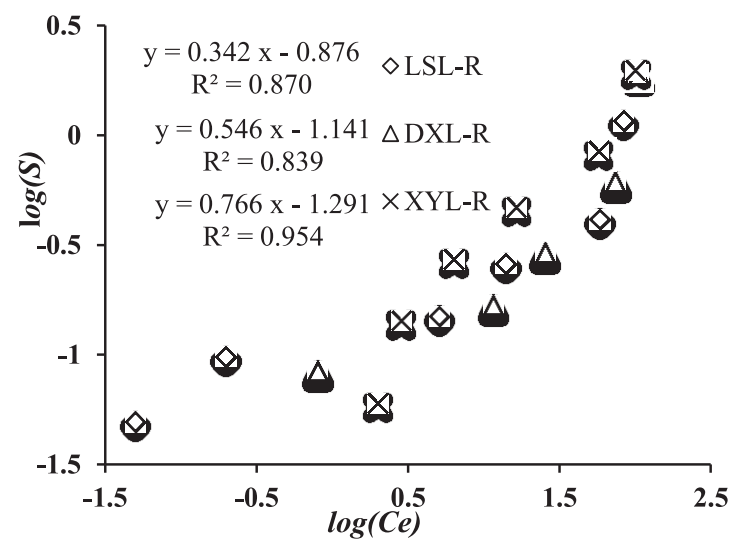

(a) Freundlich

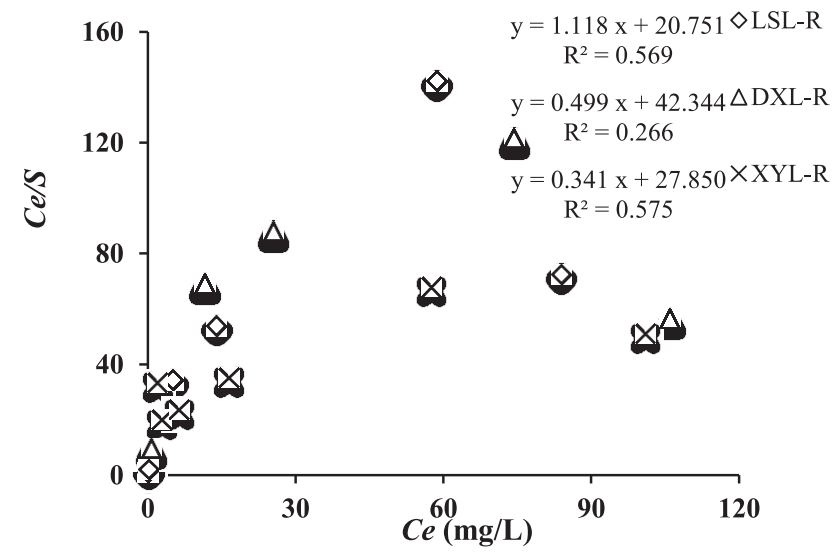

(b) Langmuir

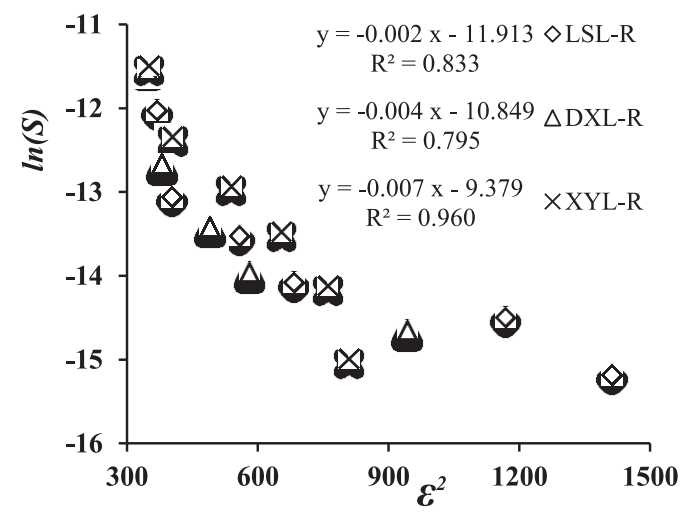

(c) Dubinin-Radushkviech

Figure 5-Freundlich, Langmuir and Dubinin-Radushkviech adsorption isotherm of DMP adsorbed on three sediments with reclaimed water

reclaimed water was more easily to be in reclaimed water rather than adsorbed on sediments, which indicates that the reclaimed water would inhibit the DMP adsorbed by sediments. The values of mean adsorption energy in the condition of reclaimed water were smaller than that of in condition of pure water, it is supposed to be the reason that the substances in reclaimed water adsorbed on sediments change the sites.

\section{Conclusions}

In this study, the adsorption behavior of DMP on three sediments from urban lakes and the effects of reclaimed water on it were investigated by using batch experiment. The model experiment results are limited to one-component system because of the given condition in this experiment. The Freundlich and Dubinin-Radushkviech models are more suitable to describe DMP adsorption on sediments than Langmuir model. The reclaimed water reduced the DMP maximum adsorption capacity because of the competition of the components in reclaimed water. The organic matters in reclaimed water were likely to combine with DMP to make DMP more readily existing in reclaimed water, and inhibiting the DMP adsorbed on sediments.

\section{Acknowledgements}

We are grateful for financial support by the Chinese National Natural Science Fund (51321001), the Program for Beijing science and technology plan projects (D090409004009004), the Ministry of Water Resources research special funds for public welfare industry project (201401054).

Submitted for publication November 16, 2014; accepted for publication August 11, 2016.

\section{References}

Abdel daiem, M. M.; Rivera-Utrilla, J.; Ocampo-Perez, R.; Mendez-Diaz, J. D.; Sanchez-Polo, M. (2012) Environmental Impact of Phthalic Acid Esters and their Removal from Water and Sediments by Different Technologies - A Review. J. Environ. Manage., 109, 164-178.

Chen, C. Y.; Chung, Y. C. (2007) Removal of Phthalate Esters from Aqueous Solution by Molybdate Impregnated Chitosan beads. Environ. Eng. Sci., 24(6), 834-841.

Chen, S. H.; Nyman, M. C. (2007) Sorption and Desorption Behavior of Benzidine in Different Solvent-Sediment Systems. Chemosphere, 66, 1523-1534.

Douglas, G. R.; Hugenholtz, A. P.; Blakey, D. H. (1986) Genetic Toxicology of Phthalate Esters: Mutagenic and Other Genotoxic Effects. Environ. Health Perspect., 65, 255-262.

Dubinin, M. M.; Radushkevich, L. V. (1947) Equation of the Characteristic Curve of Activated Charcoal. Proc. USSR Acad. Sci., 55, 331.

Den, W.; Liu, H. C.; Chan, S. F.; Kin, K. T.; Huang, C. (2006) Adsorption of Phthalate Esters with Multiwalled Carbon Nanotubes and its Applications. J. Environ. Eng. Manage., 16(4), 275-282.

El-Kamash, A. M.; Zaki, A. A.; El-Geleel, M. A. (2005) Modeling Batch Kinetics and Thermodynamics of Zinc and Cadmium Ions Removal from Waste Solutions Using Synthetic Zeolite A. J. Hazard. Mater., 127, 211-220.

Foster, A. L.; Katz BG.; Meyer, M. T. (2012) Occurrence and Potential Transport of Selected Pharmaceuticals and Other Organic Wastewater Compounds from Wastewater Treatment Plant Influent and Effluent to Groundwater and Canal Systems in Miami-Dade County, Florida; Scientific Investigations Report 2012-5083; United States Geological Survey: Reston, VA.

Freundlich, H.; Hatfield, H. S. (1926) Colloid and Capillary Chemistry, 1st ed.; Methuen: London.

Foo, K. Y.; Hameed, B. H. (2010) Insights into the Modeling of Adsorption Isotherm Systems. Chem. Eng. J., 156, 2-10.

Gledhill, W. E.; Kaley, R. G.; Adams, W. J.; Hicks, O.; Michael, P. R.; Saeger, V. W.; LeBlanc, G. A. (1980) An Environmental Safety Assessment of Butyl Benzyl Phthalate. Environ. Sci. Technol., 14, 301-305. 
Gan, Y. P.; Bai, Y. (2010) Advanced Treatment and Recycling Technology in Wastewater Treatment Plant; China Building Industry Press: Beijing.

Gao, P.; Feng, Y. J.; Zhang, Z. H.; Liu, J. F.; Ren, N. Q. (2011) Comparison of Competitive and Synergetic Adsorption of Three Phenolic Compounds on River Sediment. Environ. Pollut., 159, 2876-2881.

Haghseresht, F.; Lu, G. (1998) Adsorption Characteristics of Phenolic Compounds onto Coal-Reject-Derived Adsorbents. Energy Fuels, 12, 1100-1107.

Hu, H. Y.; Wu, Q. Y. (2011) Reclaimed Water Quality Safety Evaluation and Protection Principle; Science Press: Beijing.

Khan, S. A.; Rehman, R.; Khan, M. A. (1995) Adsorption of Chromium (Ill), Chromium (VI) and Silver (I) on Bentonite. Waste Manage., 15(4), 271-282.

Li, B.; Qian, Y.; Chen, H.; Schmidt, T. C. (2010) Sorption Behavior of Phthalic Acid Esters on Reference Soils Evaluated by Soil Column Chromatography. Soil Air Water, 38(5-6), 425-429.

Li, Y. K. (2012) Environmental Impact of Recycled Water to Yongding River for Ecological Use and Key Technology Study. China Water Res., 5, 30-34.

Laus, R.; Costa, T. G.; Szpoganicz, B.; Fávere, V. T. (2010) Adsorption and Desorption of $\mathrm{Cu}(\mathrm{II}), \mathrm{Cd}$ (II) and $\mathrm{Pb}$ (II) Ions using Chitosan Cross Linked with Epichlorohydrin-Triphosphate as The Adsorbent. J. Hazard. Mater., 183, 233-241.

Langmuir, I. (1918) The Adsorption of Gases on Plane Surfaces of Glass, Mica and Platinum. J. Amer. Chem. Soc., 40(9), 1361-1403.

Mitra, S.; Bhowmik, P. C.; Xing, B. S. (1999) Sorption of Isoxaflutole by Five Different Soils Varying in Physical and Chemical Properties. Pestic. Sci., 55, 935-942.

Metwally, E.; El-Zakla, T.; Ayoub, R. R. (2008) Thermodynamics Study for the Sorption of Cs and Co Radionuclides from Aqueous Solutions. J. Nucl. Radiochem. Sci., 9, 1-6.

Osman, B.; Özer, E. T.; Demirbel, E.; Güçer, S.; Besirli, N. (2013) Synthesis and Characterization of L-Tryptophan Containing Microbeads for Removal of Dimethyl Phthalate from Aqueous Phase. Sep. Purif. Technol., 109, 40-47.

Osman, B.; Özer, E. T.; Kara, A.; Güçer, S.; Besirli, N. (2012) Assessment of Dimethyl Phthalate Removal from Aqueous Phase Using Barium Hexaferrite Containing Magnetic Beads. J. Colloid Interface Sci., 378, 167-174.

Staples, C. A.; Peterson, D. R.; Parkerton, T. F.; Adams, W. (1997) The Environmental Fate of Phthalate Esters: A Literature Review. Chemosphere, 35, 667-749.

Van Riemsdijk, W. H.; Bolt, G. H.; Koopal, L. K. (1986) Electrolyte Adsorption on Heterogeneous Surfaces: Adsorption Models. J. Colloid Interface Sci., 109, 219-228.

Xia, X.; Zhang, J.; Sha, Y.; Li, J. (2012) Impact of Irreversible Sorption of Phthalate Acid Esters on their Sediment Quality Criteria. J. Environ. Monit., 14, 258-265.

Yang, F.; Wang, M.; Wang, Z. Y. (2013) Sorption Behavior of 17 Phthalic Acid Esters on Three Soils: Effects of $\mathrm{pH}$ and Dissolved Organic Matter, Sorption Coefficient Measurement. Chemosphere, 93, 82-89.

Zhang, W.; Xu, Z.; Pan, B.; Lv, L.; Zhang, Q.; Zhang, Q.; Du, W.; Pan, B.; Zhang, Q. (2007) Assessment on the Removal of Dimethyl Phthalate from Aqueous Phase Using a Hydrophilic Hyper-Cross-Linked Polymer Resin NDA-702. J. Colloid Interface Sci., 311, 382-390. 